(11) (البحث رقم

\title{
أثثر برنامج للثقافة البصرية على تنمية الإبداع الفني \\ لاى بعض الفنانات في منطقة عسير
}

\author{
إعــــــــد \\ أز علا احمد علي العاصمي \\ محاضر في تخصص التربية الفنية - كلية الثربية \\ جامعة الدمام - المملكة العربية السعودية
}


كانت الفنون منذ نشأتها تعبير ا اجتماعيا وجماليا عن أوضاع المجتمعات الأخرى في شنى العصور ، فهي وليدة تفاعل الإنسان مع البيئة. فهي حصبلة لانفعالاته، ومشاعره،

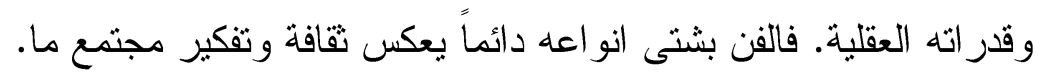

و الفنون بهذه الصفة تحمل في طياتها مقومات الثقافة. لذلك تعد مجمل التز اث

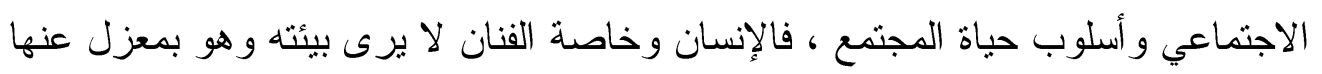
، فهو في الحقيقة، يصور ما في بيئته ،ويجسدها ، ويخلدها في أعماله القنبة.

أما الثقافة الفنية فتعني جميع الاتجاهات القديمة و الديثة في رؤية الفن ، بمعنى كل المعارف و المعلومات التي يمكن دراستها ونحليلها ونقدها من خلال الممارسة الفنية للفنان، و التي تظهر في أدائه الفني تؤثر فيه ويؤثر فيها.

ويعتبر الفن الثتكيلي من أهم المجالات المتتمدة على الروية الفنية وخاصة البصرية

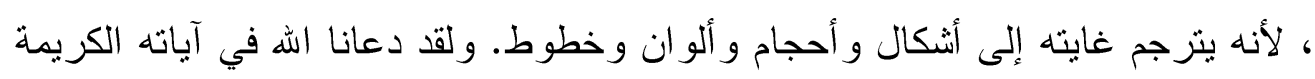

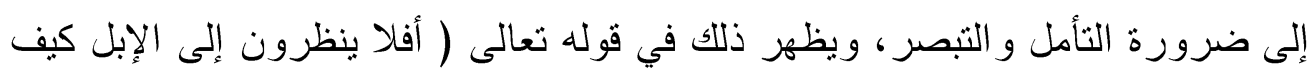

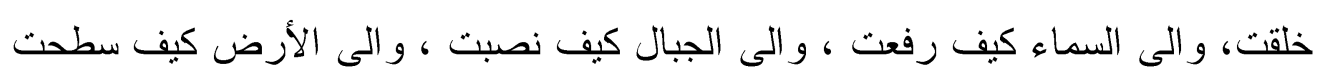

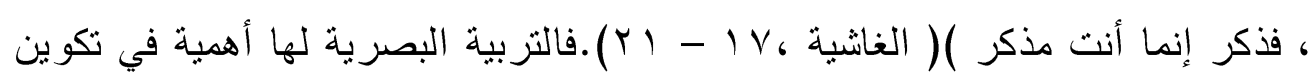

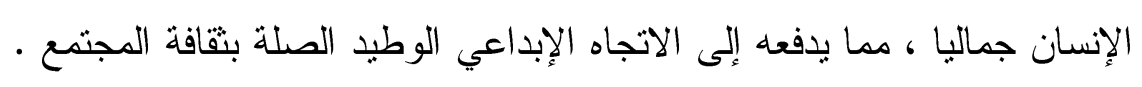
فنقافة العين ضرورة لإدر اك العلاقات الجمالية و التي بدور ها تغدي الرؤية الفنية.

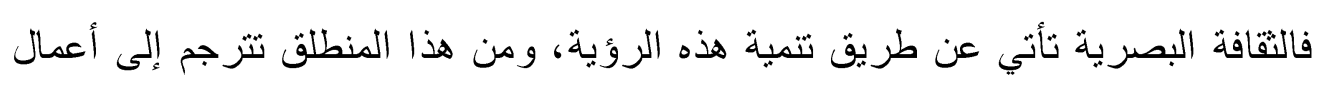

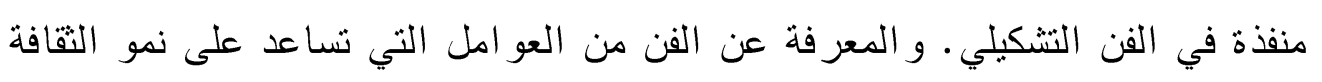

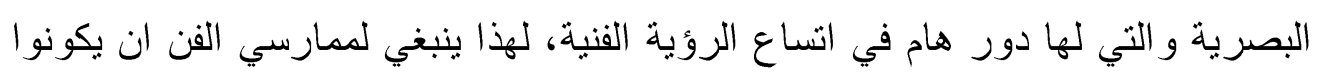


قادرين على ربط انو اع من المعرفة بالفنون و المهار ات من خلال و عبر مجالات الفنون المختلفة ، عن طريق فهم الانتاج الفني و التاريخ و الثقافة (ي 99 (Naea).

يعد الإبداع من الأمور التي حاول الكثير من المفكرين و الفلاسفة و الفنانين تقسيرها ، فالبعض ذهب إلى القول أنها نوع من الوحي و الإلهام ، ومنهم من عاد بها إلى قوة العقل و الفكر، ومنهم من تلمس أصولها في ثنايا المجنمع ،و منهم من وصل بين هذه الأصول وبين السيكولوجيا أو اللاشعور على جهة خاص (عبد المعطي بهو (م) ـ فالإبداع الفني ينطلق من إحساس وجداني قابل للتحليل النفسي ، و تقاس درجات هذا الإبداع بمقدار ما يمتلكه الفنان من تخيل و إحساس قويين مقترنين بخبرته الفنية السابقة . و بما أن الثقافة سلوك يعلم ، فدر اسة الفن تساعد على نمو الثقافة بصفة عامة و الثقافة الفنية البصرية بصفة خاصة، و هذا ما تنادي به الاتجاهات المعاصرة للتربية الفنبة في بناء بر امجها و التي تهدف إلى تدريس الفن بوصفه مادة در اسية DBAE ،ويركز هذا الاتجاه على الفن كنظام يؤكد على أهمبة توازن وتز ابط أربعة محاور " تاريخ الفن ، النقد الفني ، علم الجمال ، الإنتاج الفني "و التي تعمل على إثراء الخبرة الجمالية عند الفرد . إن الثقافة البصرية لاى الفنان تزيد ذخيرته من المفردات و الأشكال البصرية ، وذلك بسهم في تنمية المقدرة على الإبداع ، و الذي هو مطلب أساسي للفنون التشكيلية. لهذا ثرى الباحثة ضرورة رعاية المو اهب الفنية ،و إثر اء ثقافتها بالمدركات البصرية من خلال برنامج إثر ائي هدفه تتمية الإبداع من خلال إثر اء المدركات البصرية للفنان التشكيلي. فالاهتمام بالموهبة في مجال الفنون التشكيلية يعتمد على تثقيف الفنان الموهوب بصريا، وزيادة ذخيرته من المفردات و الأشكال البصرية ،التي تحفز على الإبداع • 


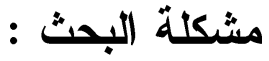

تهنم "قرية مفتاحه النشكيلية "بمركز الملك فه الثقافي في أبها بالفنون النتكيلية و الفوتو غر افية، حيث تسنقطب محبي الفنون لممارسة أعمالهم الفنية في بيئة مناسبة تلائم تطلعات هؤ لاء الفنانين و المبدعين. ولم تقتصر الأنشطة في السنو ات الأخيرة على الفنانين فقط ، بل اهنمت بالفنانات النشكيليات بمنطقة عسير من خلال المشاركة في المعارض الفنية. حيث اتسمت أعمالهن بالفطرة و التلقائية دون الأخذ في الاعتبار أسس وقو اعد الفن التشكيلي.

و قد لاحظت الباحثة مدى حماسهن لمعرفة أوجه الفن المختلفة ،و من خلال مناقشتهن لبعض الأعمال الفنية وجدت الباحثة قصور في الثقافة الفنية و النشكيلية لديهن. و على الرغم

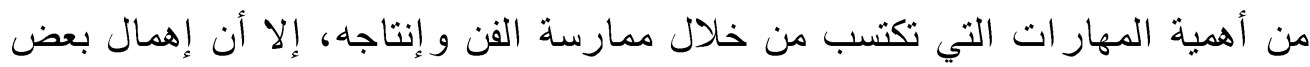
جو انبه الهامة، مثل اكتساب المعارف و المعلومات عن تاريخ الفن وكذللك مهارة النقد الفني و علم الجمال ، يؤدي إلى عدم اكتساب القدر الكافي من فهم السياق الثقافي الذي يعمل الفنان وفقا له .

و لأنه نادى الكثير من العلماء في حقل التزبية الفنية بتدريس الفن كمادة اكاديمية "DBAE" اعمق للفن، نظر اً لاحتو ائها على الجو انب النظرية و التقنية و التي تلعب دور اً كبيراً في تتمية

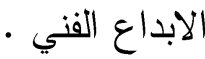

لذا اقترحت الباحثة وضع برنامج إثر ائي في الثقافة البصرية مبني على اتجاه المعرفة المنظمة "DBAE " و الهدف منها تتمية الإبداع الفني، وذللك بإثر اء رؤية الفنانة بصريا وتتمبة الجانب الإبداعي لديها. وتصاغ المشكلة في التساؤل الآتي: 
ما اثر برنامج للتقافة البصرية على تتمية الإبداع الفني لاى بعض الفنانات التشكيليات في منطقة عسير؟

تكمن أهمية هذا البحث في الارتقاع بالمستوى الثقافي و المهاري للفنانة التشكيلية في منطقة عسير ، وذلك بتزويد الفنانة التشكيلية بأهم الاتجاهات الحديثة في" الفن الحديث" من خلال بل بله نظرية المعرفة المنظمة " DBAE "، و التي تساهم في إثراء رؤية الفنانة التشكيلية بصريا، مما يساعد في تتمية الإبداع الفني لديها. فروض البحث: تفرض الباحثة انه يمكن : - ت

ا. در اسة بعض الاتجا هات الفنية الحديثة المبنية على نظر ية المعر فة

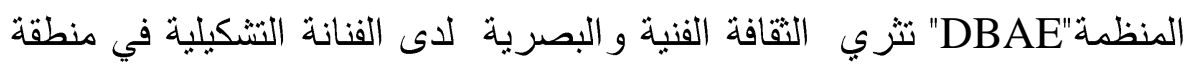
• عسير r. يساعد البرنامج الإثر ائي على تتمية القدرات الإبداعية لاى الفنانة التشكيلية في منطقة عسير

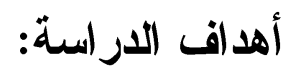

1. التعرف على بعض الاتجاهات الفنية الحديثة من خلال إتباع نظرية المعرفة " DBAE " المنظمة r. التعرف على اثر برنامج إثرائي في الثقافة البصرية في تتمية القدرات الإبداعية للفنانة في منطقة عسير في مجال التصوير التشكيلي. حدود الار اسة :

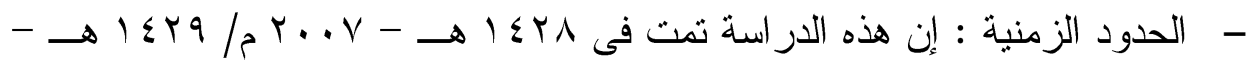
$. r . . \Lambda$ 
- - الحدود المكانية :إن هذه الدراسة تمت في قرية مفتاحه التشكيلية بمركز الملك فهر

$$
\text { الثقافي في أبها. }
$$

- - الحدود الموضوعية: اثز برنامج للثقافة البصرية على تتمية الابداع الفني.

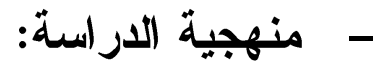

اتبعت الباحثة كل من المنهج الوصفي شبه التجريبي.

\section{مجتمع الار اسة : مجية}

الفنانات التشكيليات بمنطقة عسير •

عينة الار اسة : ع

سبعة "Y" فنانات نشكيليات من منطقة عسير .

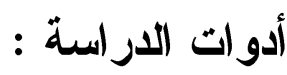

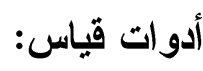

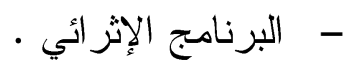

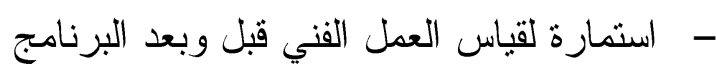

- - اختبار "تور انس" للتقكير الابتكاري الصور (أ) بالأشكال.

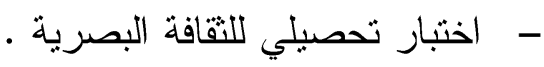

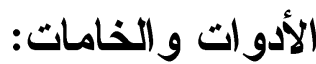

- ـ الخامات و الأدو ات ( ألوان زيت _ قماش مشدود _ فرش ) 


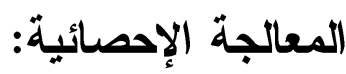

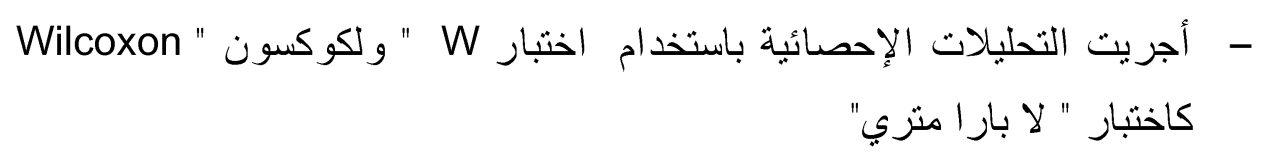

مصطلحات الدر اسة:

الثقافة :

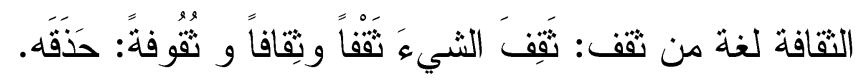

الثقافة في المعجم الوسيط "هي العلوم و المعارف و الفنون التي ينطلب الحذق فيها " (المعجم الوسيط سV (9) (م).

الثقافة هي طريقة الحياة في المجتمع بجو انبها المادية كالآلات و الإنشاءات و الأزياء و غيرها ، و المعنوية كاللغة و الأدب و الفن و الدين وغيره، كما أنها تتمثل في طريقة التقكير و أنماط وياط الفكر وفي المعتقدات و التوقعات و العلاقات التي تتظم تعامل الناس في حياتهم وفي أنماط السلوك و مصطلحاته بين الناس المجنمع (سرحان، 999 (م)

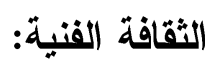

الفنون على اختلاف أنو اعها مجالات حية للثقافة ،فالعامل الثقافي من العو امل الهامه التي تلعب دور ا مهما لـأن عدم الثقافة الفنية تؤدي إلى قتل الإبداع و الإنسان متثقف حتى يصل

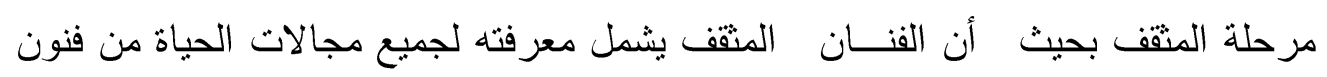
شعبية وثقافات تقليديــة و وتاريخ فن بشرط أن يكون ملماً بثقافة المجتمع وعلومه المختلفة و وكذلك ان يكون ملماً بعالم الجمال و النقد الفني ومعرفة المهار ات و الاطلاع على العدد. و الادوات و التي تعد من العو امل المؤثرة على الفن و على التكوين البصري ( الحسن 
هي جملة من الكفايات البصرية يسنطيع الفرد أن ينميها عن طريق التكامل بين حو اسه الخمسة ، و هي تمكنه من تمييز الأشياء و الرموز و الأحداث التي تقابله في حياته وتقسيرها ثم استخدامها إبداعيا في تو اصله مع الآخرين (عبد الحليم و99 (م) . وتعرف إجر ائيا بأنه الإثر اء البصري للفنانة بكل ما يتعلق بالفن الحديث وما يرتبط به من اتجاهات مختلفة ورو ادها الفنانون في مجال التصوير التشكيلي ، كما يدخل في ذللك الأسس الفنبة للبناء التشكيلي للأعمال الفنية من تكنولوجيا الخامات وأساليب التعبير الفني ، وذلك من خلال إتباع اتجاه المعرفة المنظمة "DBAE".

\section{الإبداع الفني :}

الإبداع الفني هو ذلك النتاج في ميادين : الموسيقى ، الأدب، الثُعر ، الفنون التشكيلية ،

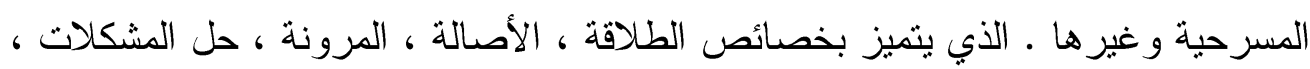
و تشكل إضافة جديدة للمعرفة البشرية في ميدان الفن (صالح الهو ام ). و تعر فه الباحثة بأنه القدرة على إبداع أثكال فنية غير تقليدية تتسم بالطلاقة و المرونة و الاصالة و التفاصيل محملة بقيم فنية وتشكيلية أصيلة . 


\section{الإطار النظري للبحث}

الثقافة :

لقد استخدم اصطلاح " الثقافة " للالالة على كل ما صنعتّه الثُعوب من نظم اجتماعية سائدة أو من عادات وتقاليد ، فهي مجمل النزاث الاجتماعي الذي هو أسلوب حياة ذلك المجتمع · ولقد ذكر (سرحان 999 (م) تعريف شامل للتقافة بأنها طريقة الحياة في المجتمع بجو انبها المادية كالآلات و الإنشاءات و الأزياء وغيرها ، و المعنوية كاللغة والأدب و الفن و الدين و غيره ـ كما أنها تتمثل في طرف التفكير و انماط الفكر ، وفي المعتقدات و العلاقات التي تنظم تعامل الناس في حياتهم وفي أنماط السلوك المختلفة .

و الثقافة تتناقلها الأجيال المتعاقبة عن طريق الاتصال اللغوي او الثكلي كالخبرة بشؤون الحباة ، وبو اسطنها يسنطيع الفرد أن يربط بين الأحداث و الزمان و المكان، ولكن نعلم عجز وقصور اللغة اللفظية مقارنة باللغة التشكيلية والتي هي لغة اتصال عالمية ، تتقل من الماضي إلي الحاضر ، وتشكل الحاجز للمستقبل تحت مسمى " الثقافة الفنية "

\section{الثقافة الفنية :}

هي ثقافة الإنسان وفلسفة المجتمع .و الفن في ذاته وعلى اختلاف صورة مرآة للثقافة بل أحد دعاماتها و اهم وسائل نشر ها. ويرى "البسيوني" إن هناللك نوعان من الثقافة الفنية :

النوع الأول : متعلق بالناحية الفنية ذاتها ، وما يرتبط بها من تكنولوجيا الخامات ، وتطويعها لعمليات التعبير و التوظيف ،التي تخدم أغر اض الفنان. 
النوع الثاني : يتعلق بالإحاطة بتبارات الفكر العامة ، المؤثرة في شكل الحياة من الأوجه الاجتماعية و الاقتصادية و السياسية ، و التي لها دور في موضو عات وطبيعة الاعمال الفنية. إن الأشكال المحيطة بالفنان والثي نمثل مظاهر البيئة من حوله أو حتى من الأشكال النازحة من الثقافات أخرى دخيلة ، غالبا هي أداة التعبير لاية ففي مجملها نتكل ما يسمى

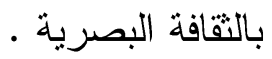

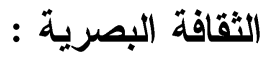

هي منظومة منكاملة من الرموز و الأشكال و العلاقات و المضامين والتشكيلات التي تحمل خبر ات ورصيد الإنسان على مر العصور ، وتزتبط الثقافة البصرية ارتباط مباشر بالتذوق الفني ، حيث يزداد مقدار وسعة التذوق الفني بازدياد قدرة الإنسان على الثقافة البصرية.

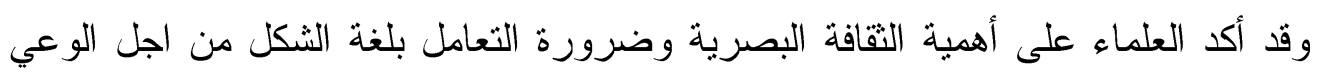
بقيمة الوسائط التعبيرية المنتشرة في البيئة المحيطة ، لان الثقافة الفنية بشكل عام تعتمد على الرؤية الفنية الثقافة البصرية .

\section{أهمية الجاتب البصري في تعلم الفن:}

أن استخدام الاتجاه البصري في طريقة تعليم الفنون هو مصدر لإثراء الخيال .وقد نادي بعض المفكرين كعنصر أساسي لتنمية التقافة البصرية لدى المتعلم لتحقيق الأهداف التربوية

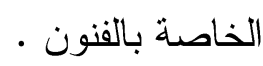

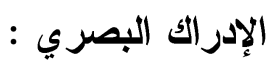

هو العملية التي تتم بها معرفتنا لما حولنا من أثنياء أو استجابات وجدانيه عن طريق حاسة البصر ـ أن الثقافة البصرية وتتمبة الإدر الك البصري تسهم في ثراء عمليات التعبير الفني لدى الفنان وبالتالي يصل الى مر احل الإبداع الفني. 
يتداخل مفهوم الإبداع مع مفاهيم أخرى الابتكار و العبقرية و الموهبة ، و عليها اختلـــ العلماء في الثميز بينها ولكن اتفقو اعلى إن جميع هذه المفاهيم تعد سلوك منقوق عـن النمط العادي.

الإبداع الفني :

يعرف الفن كنشاط إبداعي ، حيث أن أهداف الفن فــي العصــر الحــديث و المفــاهيم الأساسية للنزبية الفنية المعاصرة يلتقبان في نقطة جوهرية ، هي الإيمان بان الغاية من ممارسة الفن تتحصر في ابتداع الصور و الأشكال الجميلة. الإبداع الفني ينأثر بثقافة الفنان و البيئة المحيطة به و الني تحوي رموز و أثنكال يعتــــ عليها الفنان كمدخل للنعبير الفني.

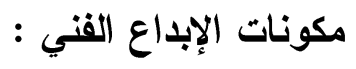

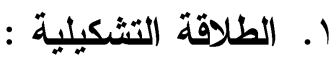

وهي تقديم أكبر عدد ممكن من الاستجابات الملائمة إزاء مشكلة أو مثير، وهناك ثلاث أنو اع رئيسية للطلاقة في السلوك الفني الإبداعي :

أ- قدرة الشخص على إنتاج أفكار عديدة عن موضوع ، وهنا يصبح لكم مهما. ب- قدرة الشخص على إنتاج أفكار عديدة عن موضوع في زمن وموقف علف معين.

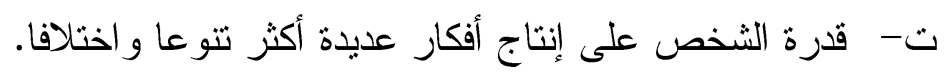

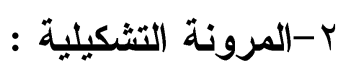

المرونة تشير إلى إنتاج أفكار في اتجاهات مختلفة ، أب ميل الفنان إلى إعادة بناء عمله الفني بسر عة وقدرته على تتويع رؤينه لشكل ما. 
وهناك مظاهر متنو عة للمرونة منها :

أ- - المرونة التلقائية : فهي تعني الابداع في اكثر من اطار او شـــل ، فـــ ثلقائيــة وتنوع.

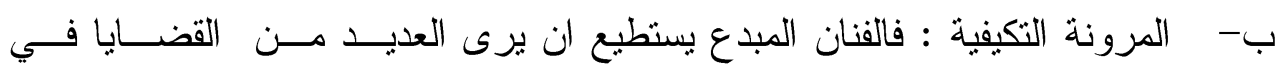
الموضوع او الموقف الو احد.

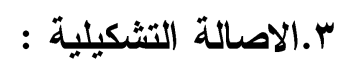

تعتبر صفة مطلقة للفنان ، لأنها عنصر اساسي في الابداع الفني وهو القابلية نحو انتاج افكار غير مألوفة، ومن مظاهرها :

- - القدرة على انتاج الافكار المألوفة بين الفنانين. - - القدرة على الربط بين الاشياء والاحداث او بين الاشياء و الرموز و المعاني. - - القدرة على اظهار المهارة في الاستجابة. ع. التفاصيل :

مدى التوضيح و الاتقان او التطوير وهي قدرة الفنان على تتاول الفكرة بطريقة تـؤدي الى تحسينها وتطويرها، مما بياعد على ابر از فكرنه الاصلية.

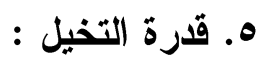

ان العالم الداخلي للفنان المبدع يكون نشيطا الى درجة عدم اعتماده على ما ينلقاه مسن مقومات الخبرة من و اقعه الخارجي فقط ، فما يتلقاه يضـاعف بو اسطة الخيــال فيثـري عقله المبدع. 


\section{צ.استمرارية الاتجاه :}

القدرة على تركيز الانتباه و التفكير طويلا ومستمر ا في مشكلة ما ، على الــرغم مــن المشتتات و المعوقات التي تثير ها المو اقف الخارجية. هذه القدرة تتعكس فــي الانتـــاج الفني العام للفنان المبدع مما يحقق له خطاً يؤكد على الشخصية الفنبة له.

تتعدد الانشطة و الاساليب التي تتمي الإبداع ، و على الرغم من ذلك الا انه يوجـــ

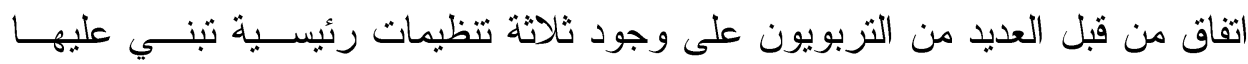
استر اتيجيات " بر امج رعاية المو هوبين " ومن هذه التتظيمات :

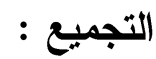

و هو من اقدم الاساليب ويقصد به تجميــع المبــدعين ذوي القـدرات او الاهتمامــات المتشابهة معا، مما تجعلهم اكثر ميلا الى الاستكثاف وتبادل الافكار.

\section{الاسر اع او التعجيل : الت}

ويعني هذا الاسلوب ان تكون سرعة التعلم و التدريس اعلى من المعدل الذي يكون علية المتعلم العادي ، وهي تتبع طرق التعليم بالمدارس.

الاثراء :

ويطلق عليها أيضا " الاغناء" ، هو تقديم برامج تثري خبرات المبدعين ، وتختلف عن البر امج التعليمية العادية وتثقوقها في الكم و الكيف و العمق و الاتساع و التخصص ، على تلى

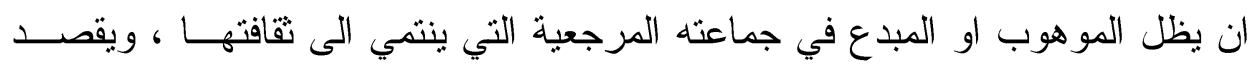
بالاثر اء" اضافة وحدات تعليمية او تدريس محتوى مختلف او استخدام وسائل تـدريس

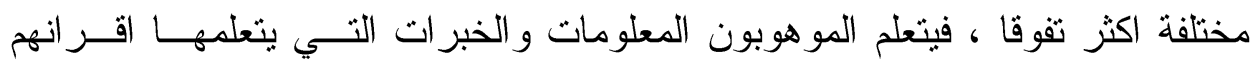


العاديين ، مضافا اليها موضو عات لتوسيع معلوماتهم وتعميــق خبــر اتهم اكثــر مــن العاديين ، وذلك لمو اجهة احتياجاتهم و اهتماماتهم وقدر اتهم المختلفة " (نور ( .. rم)

وتتضمن بر امج الاثر اء انشطة تهدف الى تتمية المفاهيم و الربط بينها وتتميــة القــدرة على حل المشكلات و على التعامل مع المو اقف المركبة وفهمها و ابتكار افكار جديدة . وتزى الباحثة ان بر امج الاثراء هي من انسب الطرق و احسنها تطبيقا في مجال الفنون التشكيلية ، وذلك لان الهدف منها تزويد الفنان بخبرات و اسعة ومعارف مكثةـــة بدرجة تحقق التحدي المطلوب لقدرات هذا الفنان ـ كما ان الفن التشكيلي يضــــــــات مختلفة من الفنانين و التخصصات المختلفة، لهذا فبر امج الاثر اء وما تحويه من انشــطة تثقيفية تعد هامة لمثل هذه الفئة من المجتمع.

\section{نظرية المعرفة المنظمة "DBAE"}

هو احد الاتجاهات المعاصرة للتربية الفنية ، و التي تهدف الى تذريس الفـن باعتبــاره اسلوب منظما ويسمى " Disipline Based Art Education " و المعروف" DBAE " وفي ترجمة مسمى هذا الاتجاه ظهر العديد من الصيغ المختلفة منها : - - التربية الفنية المبنية على الفن بوصفه مادة دراسية . - تدريس التزبية الفنية على اساس معرفي علمي • - م المعرفة كأساس للتربية الفنية - - - التزبية الفنية النظامية - المصدر المعرفي ( التزبوي، الفني) كأساس النزبية الفنية

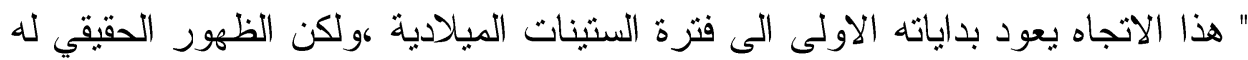

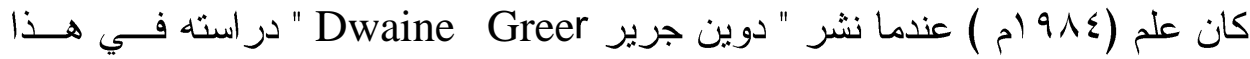
الاتجاه في مجلة " دراسات في الثزبية الفنية " التي تعد من اوسع المجــلات العلميــة

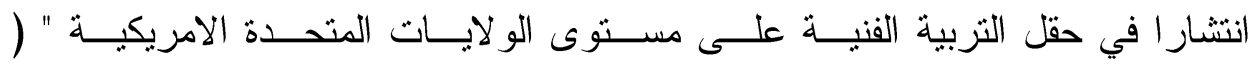


العودي + . rم) • ويركز هذا الاتجاه على الفن كنظام من خلال اربع ميادين اساسية هي اولا : الانتاج القني :

فالممارسة الفنية من اهم اهداف التربية الفنية ، فيتناول فيها الاساليب الفنبـــة المختلفـــة و التقنيات و الاجر اءات و استخدام الخامات و الادو ات المتتوعة بهدف اكتساب المهــار ات التي تساعد على ممارسة الفن ، ويرتبط الانتاج الفني عادة بالنو احي الابداعيــة ، لــــا فانه اكثر الميادين شيوعا في تدريس الفن.

" هناك بعض الحقائق المرتبطة بهذا الميدان بمكن تلخيصها كالاتي :

ا ـ الانتاج الفني يحنل المكانة الاولى في مناهج التزبية الفنية

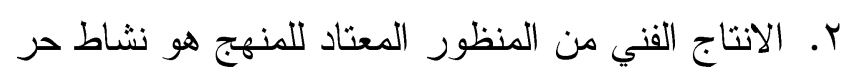

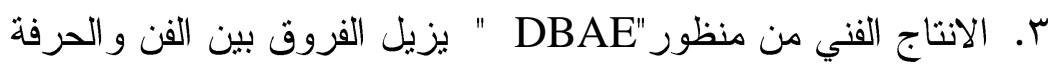

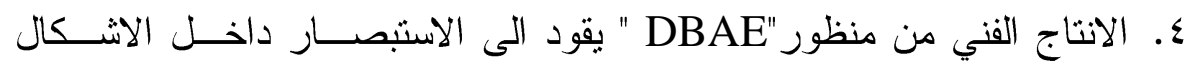

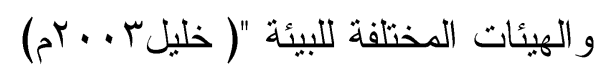

ثانيا : تاريخ الفن : بان

إن تاريخ الفن مجال يزخر بالمعلومات و الحقائق، والتي قد تحفز على التجريب و النقل و المحاكاة في بادئ الأمر ثم التمكن من المهارة التي تــؤدي بــــورها إلــى الابتكـــار

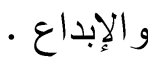

ويعد ثاريخ الفن فرع من فروع المعرفة التي تتضمن البحث و الاستقصــاء ، بهـــف اكتساب القدر الكافي من الثقافة الفنية. 
و النقد الفني يعني إبراز ما في العمل الفني من مضامين مناقشاتها بشـــل موضـــوعي لإظهار جو انب القوة وجو انب الضعف فيه و إتاحة الفرصة للمتعلم لمناقشة العمل الفني. " و هنالك بعض الحقائق التي تزتبط بمهنة النقد الفني : 1. النقد الفني هو قدرة على إصدار الأحكام الجمالية المرتبطة بالإبداعات الفنية r. النقد الفني وظيفة عقلية وتربية ذهنية

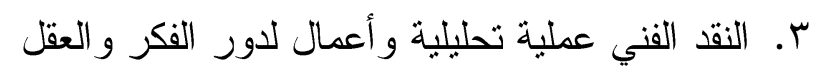
ع. النقا الفني يحدد قيمة العمل الفني ه. النقد الفني هو عملية تتمية للتذوق الجمالي و الارتقاء به لفهيه

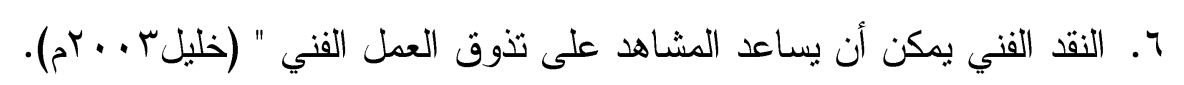

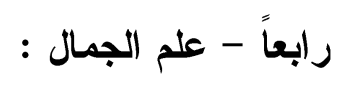

هو احد فروع الفلسفة التي تهنم بالقنون التشكيلية. إن التذوق عملية مكتسـبة فـالمتعلم بكتسبها وينميها من خلال فهم و إدر الك الأعمال الفنية، وما تحنويه من عناصر . "و هناك عدد من الحقائق المرتبطة بمفهوم علم الجمال:

1. التذوف الفني نوع من الاستجابة الوجدانبة لمؤثرات الجمال في العمل الفني

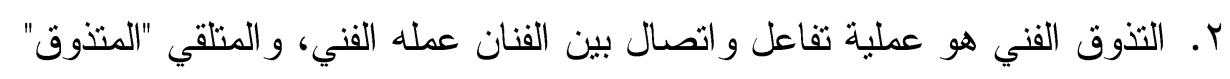
r. التذوق الفني ضرب من ضروب الحكم على العمل الفني

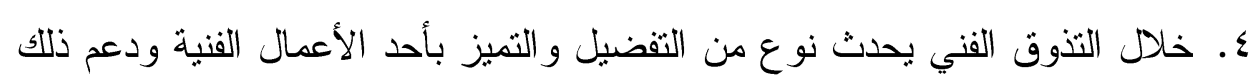

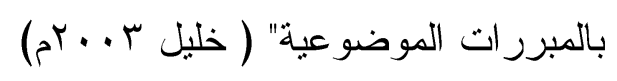

لهذا يجب على معلم الفن، أن يدرس الجوانب الجمالية ،عن طريق طرح الأسئلة وليس عن طريق السعي إلى الحصول على إجابات محددة لها. 
إن هذه الميادين الأربعة تعمل بشكل متداخل ومتر ابط فلا يمكن فصل أي فرع منهــا

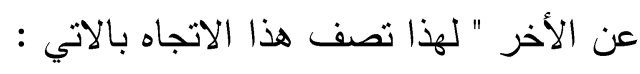

ا ب. يمثل اتجاها تدريسا شاملا للفنون التشكيلية و الأدائية

r. ب. يهدف إلى تتمية مفهوم المنعلم عن الفن من خلال خطط النتريس المنظمة

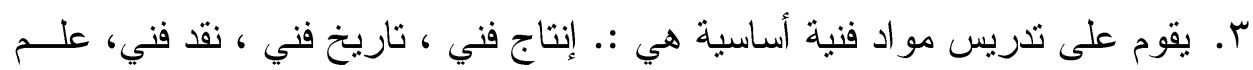

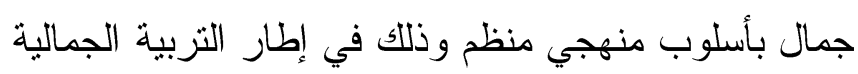

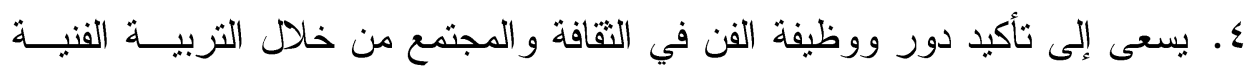

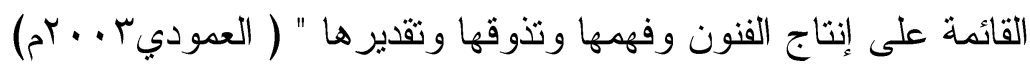

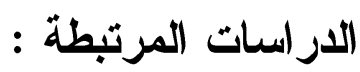

هناك العديد من الدراسات في مجال النقافة البصرية و الإبداع الفني ، وقد اختلفت مداخل

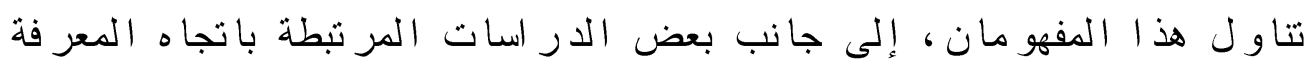

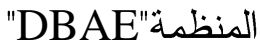

وسوف تستعرض الباحثة بعض هذه الدراسات المرتبطة بطبيعة البحث الحالي:

أولا : دراسات تناولت الثقافة البصرية:

دراسة بعنوان" اثر تعليم الفن على نمو الثقافة الفنية البصرية لطلاب كلية التربية الفنية " وقد تتاولت الباحثة فيها اثر تعليم الفن على نمو الثقافة البصرية لدى طلاب الفرقة الأولى و الخامسة من كلية التزبية الفنية ، و التعرض كنلك لمداخل الفن.

وتهدف الدر اسة إلى الكثف عن كيفية تنمية النقافة البصرية من خلال الفن التشكيلي .

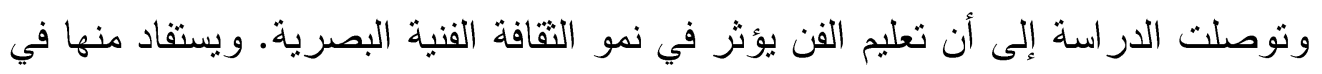
تحليلها لأثر تعليم الفن على نمو الثقافة البصرية (إبر اهيم .. بام). 
دراسة بعنوان " دور الثقافة البصرية في إثراء التذوق القني لدى فئة من الأميين " وقد تتاولت الباحثة فيها أهمية الدور الذي تلعبه الثقافة البصرية في تتمية قدرات الأفراد وخاصة الأميين بصريا وتهدف الدر اسة إلى تصميم برنامج لمحو الأمية البصرية يساعد على تتمية التذوق الفني لدى الأفر اد الأميين ـ ومن أهم نتائجها انه يمكن للثقافة البصرية أن تتقل بين الفئات الإنسانية ،وان التذوف الفني يعمل على إثراء هذه الثقافة البصرية وتتمية المفاهيم الجمالية وتتمية الإدر الك البصري. ويستفاد من هذه الدر اسة في تخطيط الوحدات الدر اسية وفي إعداد البر امج الاثر ائية و الاعنماد على الطبيعة كمصدر للأعمال الفنية

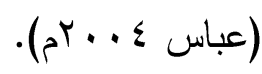

دراسة بعنوان "اثر الروية البصرية المباشرة للعمل الفني على مستوى التحصيل المعرفي

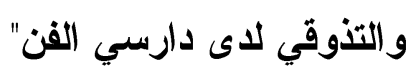

وتهدف الدراسة إلى تأكيد الدور الهام للزيار ات الميدانية للأعمال الفنية كضرورة حتمية في تكوين شخصية الطالب الفنية وثربيته جماليا و الكثف عن دور الرؤية البصرية المباشرة ومدى تأثثرها على الارتقاء بمستوى الطالب المعرفي و التذوفي.

و يستفاد من هذه الدر اسة في تأكيد ها لأهمية إثز اء مدركات دارسي الفن بصريا بشكل مباشر ، وهو ما يساعد الفنانة في منطقة عسير على تتمية الجانب المعرفي و التذوقي لها من خلال ربطها بقرية مفتاحة التشكيلية وما تحتويه من مثير ات بصرية (احمدr . . rم).

دراسة بعنوان " التدريب المعزول في مجال التربية الفنية ومردوده البصري على الطلاب

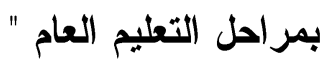

تهدف الدر اسة إلى أهمية تعدد مجال الرؤية البصرية وضرورة الاتصال بين المتعلمين و البيئة المحيطة بهم لزيادة عدد المدركات البصرية لديهم. وتوصلت نتائجها إلى أن إثر اء المدركات الشكلية بصريا للطالب ينمي جو انب التعبير الفني لديه ـ ويستفاد من هذه الدر اسة 
في ربط الفنانة في منطقة عسير بالإطار البيئي المعاش وكيفية الاستفادة منه بصريا

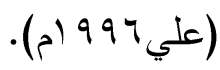

\section{ثانيا : دراسات تثاولت البرامج الاثرائية :}

دراسة بعنوان " تصميم ويناء برنامج لرعاية الطلاب الموهوبين في مجال العلوم بالمملكة العربية السعودية في ضوء نموذج " عملية المنهج".

تهدف الدراسة إلى صياغة فلسفة برنامج رعاية الموهوبين في مجال العلوم وتصميم نموذج لبناء هذا البرنامج الاثر ائي. ويستفاد من هذه الدر اسة بشكل عام في الإطلاع على مفهوم البر امج وخاصة الاثر ائية منها وكيفية تصميمها (قنديل r . . rم).

در اسة بعنوان " تصميم برنامج للنشاط في الفنون التثكيلية للطلاب الجامعيين غير المتخصصين في الفن وفق الاتجاهات الحديثة في تعليم الفنون "

وقد تتاولت الباحثة فيها أهمية بر امج الأنشطة الفنية النتكيلية بالكليات غير المتخصصة، وتهدف هذه الدر اسة إلى الكثف عن الأسس التي يستند إليها برنامج للنشاط الفني التشكيلي في ضو ء اتجاه "DBAE" حيث يو ازي بين الممارسات الفنبة وميادين المعرفة من نقد فني

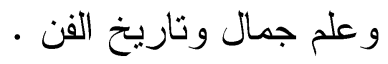

وتوصلت هذه الدر اسة إلى انه من أسباب عدم المشاركة في الأنشطة الفنية هو عدم تقهم الفنون الحديثة وفلسفتها وهو ما يؤكده دور المعارف و المعلومات التاريخية و المهار ات النقدية للتعريف بهذه الفنون

و تمت الاستفادة من هذه الدر اسة في كيفية الاعتماد على اتجاه "DBAE" في البرنامج المقتر ح للبحث الحالي وخاصة إن العينة منتابهة من حيث عدم التخصص في الفن (خليلr . . rم). 
در اسة بعنوان " برنامج مقترح لاكتثاف ورعاية الموهوبين في الفنون البصرية في مصر "

تهاف الدر اسة إلى تصميم برنامج لاكتثاف ورعاية المو هو بين في الفنون البصرية في

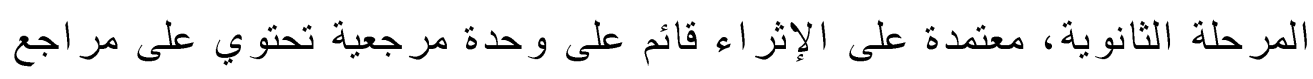
وقر اءات ومصادر للتعلم تمكن الطالب للجو إليها و اعتمدت في تصميم هذه الوحدة التعليمة "DBAE" على اتجاه "DBAE" ويستفاد منها في الاطلاع على كيفية بناء البرنامج الاثر ائي من خلال اتجاه

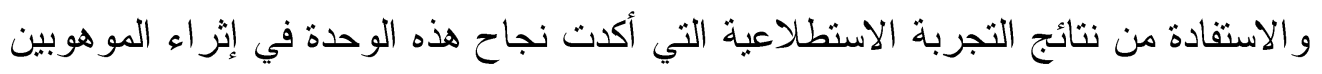

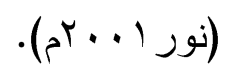
ثالثا : دراسات تناولت الإبداع الفني:

دراسة بعنوان " سمات شخصية الطالب المبدع في مجالات الفنون التثكيلية في الكويت" تهدف الدر اسة إلى تحديد سمات الثخصية المبدعة في الفنون التنكيلية ـ ومن نتائجها إن

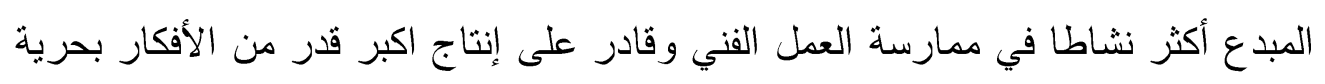
وتنائية وبطلاقة .

يستفاد من هذه الدر اسة في الإطلاع على نظريات الإبداع وربطها بالإنتاج الفني ، كما

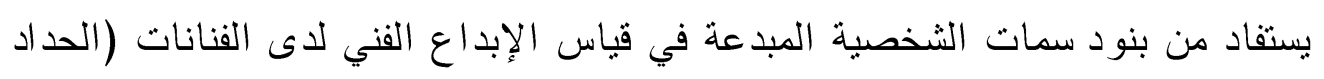
. (5r)... 
دراسة بغنوان "تنمية الخيال والإبداع من منظور تكاملي لدى مجموعة من التلاميذ في

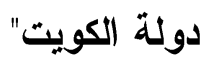
تهدف إلى معرفة علاقة الإبداع بالخيال ، وتوصلت نتائجها إن أهم جو انب اهتمام المبدع

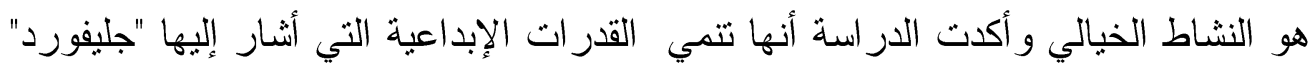
و "تور انس" من أهم تلك القدر ات الطلاقة و المرونة و الاصالة ،ويستفاد منها في بناء استمارة قياس العمل الفني(حنورة لو 199 (م)م).

دراسة بعنوان " العلاقة بين القدرة على الإتتاج الابتكاري وعدد من القيم الثخصية والقيم

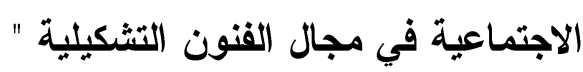

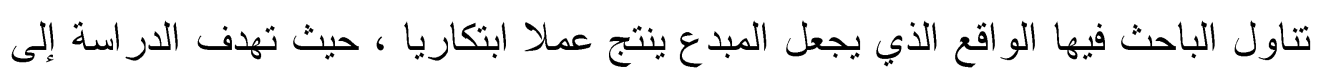
الكشف عن العلاقات بين القدرة على الإنتاج الابتكاري و عدد من القيم الثخصية و القيم

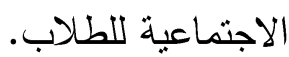

وتوصلت الدر اسة إلى أن تتوع الخبر ات يدفع المبنكر إلى ترك القديم و البحث عن الجديد

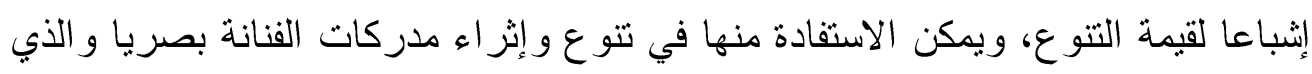
بساهم بدوره في تتمية قدر اتهم الإبداعية (عبد الغفار ع 9 (م). 


\section{رابعا: الار اسات الأجنبية : \\ در اسة بعنوان: - 20 - 20}

"Teaching Visual Culture. Curriculum, Aesthetics and the Social Life of Art"

تتاول فيها الباحث أهمية التثقيف البصري في علم الجمال وربطها بــالمجتمع وان الفنــون الجميلة جزء من هذه الثقافة، فتعرض إلى أصول تعليم الثقافة البصرية فــي تعلـيمِ الفــن وقضايا تعليم الفن. Fredimin r... ( )

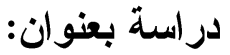

"Teaching Art in the Context of Culture: A Study in the Borderlands"

تناولت فيها الباحثة در اسة للثقافات المختلفة وربطها بالفنون، فهدفت إلى تعليم الفن ضمن السياق الثقافي (التتوع الثقافي) و اثر البيئة المحيطة بالإنتاج الفني. (Carber, 1990) 


\section{اجراءات الار اسة الميدانية:}

تسعى هذه الدراسة إلى معرفة أثر برنامج للنقافة البصرية على تتمية الإبداع الفني

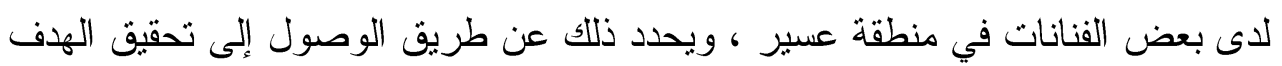

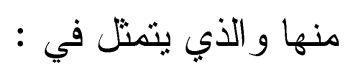

ا. التعرف على بعض الاتجاهات الفنية الحديثة من خلال إنباع نظرية المعرفة

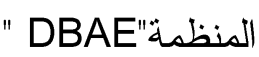

r. التعرف على اثر برنامج إثر ائي في الثقافة البصرية في تنمية القدر ات الإبداعية

للفنانة في منطقة عسير في مجال التصوير التثنكيلي.

ولتحقيق ذلك اتبعت الباحثة الإجر اءات الثالية :

أولا :منهجية البحث: اتبعت الباحثة كل من المنهج الوصفي و الثبه تجريبي ،فالمنهج

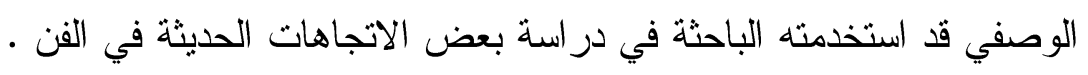

بينما المنهج الثبه تجريبي استخدمته الباحثة على البرنامج الإثر ائي الذي طبق على عينة

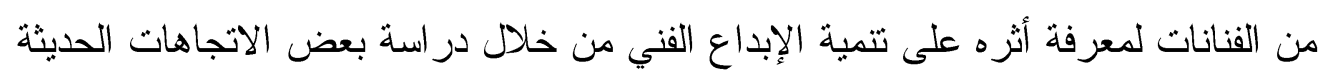

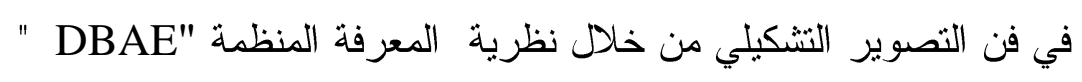

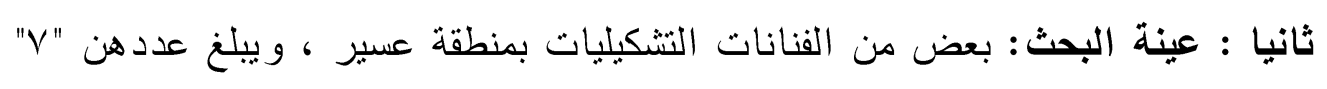

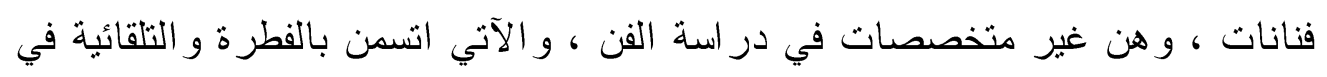

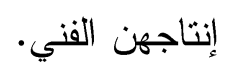

ثالثا : أدوات البحث: ويشمل البحث على عدة أدوات وهي

أدوات قياس: البرنامج الاثرائي - اختبار "تور انس" للتفكير الابتكاري - اختبار تحصيلي -

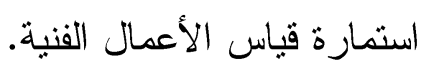




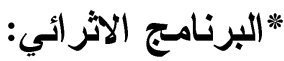

قامت الباحثة بتصميم برنامج لإثر اء الثقافة البصرية لدى الفنانــة فــي مجــال التصــــير التشكيلي بعنوان " دراسة بعض اتجاهات الفن الحديث في مجال التصوير" بهـدف إثـراء الثقافة الفنية و البصرية لدى " سبعة " من الفنانات التشكيليات بمنطقة عسير ، وذلك فـي " خمسة " مقابلات ، تستغرق المقابلة الو احدة "ساعتان" وفي كل مقابلة تعرض مدرسة فنــــة يتم التطرق لتاريخها وفلسفتها و اهم رو ادها و أعمالهم الفنية ودر استها بشكل جمالي ونقدي، وذلك في مرسم الفنانات في قرية مفتاحة التشكيلية .حيث طبق هذا البرنــامج مسن خــلال نظرية المعرفة المنظمة "DBAE " ،في بعض الاتجاهات الفنية و التي حسددت كـالآتي: ( المدرسة الو اقعية - المدرسة التأثنرية - المدرسة التكعيبية - المدرسة السريالية - المدرسة

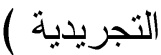

و اختيرت نظرية المعرفة المنظمة "DBAE " في هذا البرنامج وذلك للأسباب التالية :

1. تعد من انسب الاتجاهات المعاصرة لتعليم الفن لغير المتخصصين مثل عينة الدر اسة ، لأنها تتمي الفرد من خلال الفن في شتى المجالات و تؤكد على تعليم

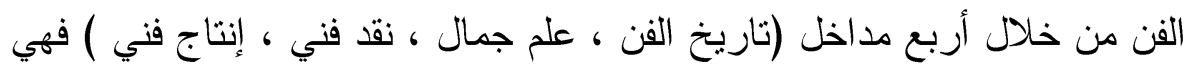
تعمل على تكامل هذه المجالات وبالتالي تقدم الفن بصورة شاملة.

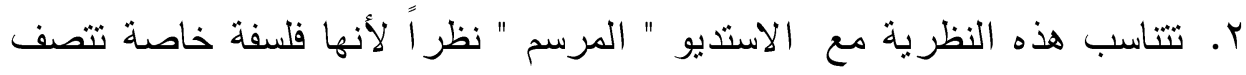
بالتز ابط العام، فلا يمكن أن يكون هناك نقد فني دون الإلمام بالتاريخ و علم الجمال

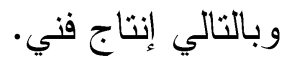

r. تتناسب مع البرنامج الإثر ائي الذي يقدم للفنانات بهدف تتمية القدرات الإبداعية . اختبار تور انس (نموذج أ):

و هو لقياس التفكير الابتكاري باستخدام الصور ، نموذج " أ "، عبارة عن " ثلاثة " أنشطة تقيس الطلاقة و المرونة و الاصالة ، وقد طبق على الفنانات بهدف قياس مدى التغير في مستوى القدرة الإبداعية قبل البرنامج الإثر ائي وكذلك بعد الانتهاء منه. 


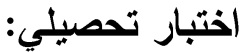

قامت الباحثة بإعداد الاختبار وهو عبارة عن مجموعة من الأســلـة التــي تقـيس الثقافــة البصرية لدى الفنانة هويتكون الاختبار من ثلاثة أجز اء ، الجزء الأول يتكون من (·r نقطة ) و المطلوب وضع علامة ( ل)اؤ(x) أمام العبارة المناسبة ـ أما الجزء الثاني ، يتكون من (0 نقاط ) و المطلوب اختبار الإجابة الصحيحة من بين الاحتمالات المتعددة المطروحسـة.أما الجزء الثالث فيتكون من ( طبق هذا الاختبار على الفنانة قبل البرنامج الاثرائي وكذلك بعد الانتهاء منه.

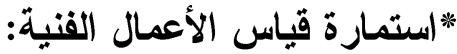

قامت الباحثة بتصميم استمارة " تقييم أعمال الفنانات التشكيليات " التي تتاولت الطبيعة، و هذه الاستمارة تقيس أعمال الفنانات قبل انضمامهم للبرنامج الإثر ائي ، وكذلك على الأعمال الفنية الني نفذت بعد البرنامج .وتتكون الاستمارة من محورين رئيسين هما :

$$
\text { r. }
$$

وكل محور يحتوي على عدد من النقاط التي تقيس العمل الفني ، فالمحور الأول يحتوي عدد من البنود روعي فيها أن تكون ملمة بعناصر العمل الفني ، أما المحور الثاني يتكون من خمسة و عشرون بندا روعي فيها أن تكون ملمة بالقيم الإبداعية.

عرضت هذه الاستمارة على مجموعة من المحكمين من أعضاء هئية التشريس بقسم التزبية الفنبة ، كلية التزبية ، جامعة الملك سعود ـ وحصلت البنود على درجة اتفاق بنسبة 10 و و عدلت بعض العبار ات فيها . 
أدوات وخامات : ألو ان زيتية - قماش مشدود ، وهي بسيطة وذللك حتى لا يكون هناك فارق بين إنتاج الفنانات قديما و إنتاجهن بعد البرنامج الإثر ائي، فهذه الأدو ات و الخامات هي

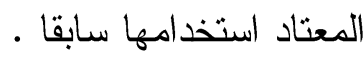

\section{وسائل تعليمية : n}

1. جهاز العرض الضوئي ، ويتم عرض صور و عبار ات هامه عن كل مدرسة فنبة في كل مقابلة لمناقشتها. r. مطو يات توضح بعض الاتجاهات الحديثة في فن التصوير و أهم رو ادها .ولكل مقابلة مطوية خاصة بالمدرسة الفنية التي تعرض. r. مصادر تعليمية ، وهي خاصة بالاتجاهات الحديثة في فن التصوير التشكيلي. رابعا : المعالجة الإحصائية :

- أجريت التحليلات الإحصائية باستخدام اختبـار Wilcoxon " ولكوكسـون W " كاختبار " لا بار ا منزي"

\section{النتائج ووصفها وتفسيرها :}

الهدف من هذه الدر اسة التعرف على بعض الاتجاهات الفنبة الحديثة من خلال إتباع نظرية الثزبية الفنية المبنية على الفن بوصفه مادة در اسية " DBAE " وكذلك التعرف على اثز برنامج إثرائي في الثقافة البصرية في تتمية القدرات الإبداعية للفنانة في منطقة عسير في

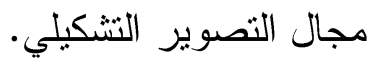
و عليه فقد افترضت الباحثة ما يلي :

1. در اسة بعض الاتجاهات الفنية الحديثة المبنية على نظرية الفن بوصفه مادة در اسية

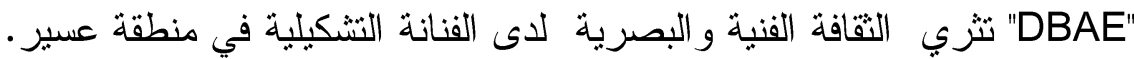
r. يساعد البرنامج الإثرائي على تتمية القدرات الإبداعية لدى الفنانة التشكيلية في منطقة 


\section{* وللتحقق من صحة الفرض الأول :}

قامت الباحثة بإجر اء " اختبار تحصيلي" للفنانات قبل تطبيق البرنــامج الإثرائسي ودر اســـة بعض الاتجاهات الحديثة في فن التصوير التشكيلي ، بهذف قياس الثقافة الفنية لــدى عينــة البحث

للإجابة عن السؤال البحثي: ما فاعلية برنامج مقترح لتنمية أداء العينة في الاختبار المعرفي $\varphi$

تم التحقق من صحة الفرض البحثي الذي ينص علي أنها يوجد فــرق دال إحصـــائًًا بــين متوسطي درجات فنانات مجموعة البحث في التطبيق البعدي، و القبلي لاختبــار التحصـيل المعرفي لصالح التطبيق البعدي".

وللتحقق من صحة هذا الفرض ثم استخدام اختبار (ولكوكسن) مع الأعداد الصــيرة مــن

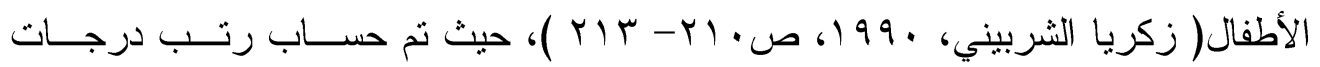

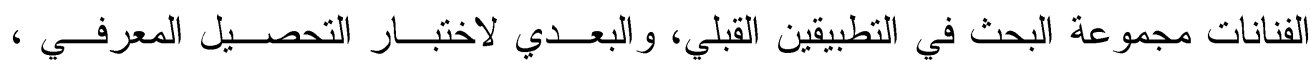

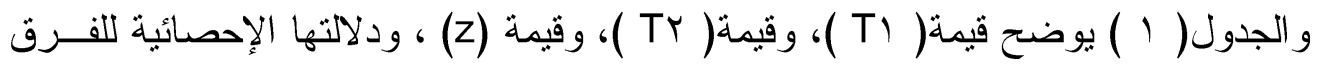
بين متوسطي رثب درجات العينة مجموعة البحث في التطبيقين البعدي، و القبالــي لاختبــار التحصيل المعرفي.

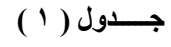

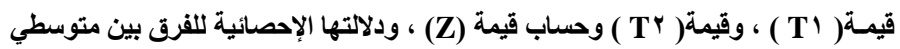

رتب درجات الفنانات مجموعة البحث في التطبيقين البعدي، والقبلي لاختبار التحصيل المعرفي

\begin{tabular}{|c|c|c|c|c|c|}
\hline الإحصائية & قيمة (Z) & قيمة (T & قيمة (T') & العدد & \\
\hline \multirow{2}{*}{ مستوي هـ هـد . } & \multirow[t]{2}{*}{ r.rvo } & \multirow[t]{2}{*}{$r \wedge$} & \multirow[t]{2}{*}{$\varepsilon$} & $\mathrm{V}$ & التطبيق القبلي \\
\hline & & & & v & التطبيق البعدي \\
\hline
\end{tabular}


يتضح من الجدول( ( ) وجود فرق ذو دلالة إحصائية عند مستوى( ( .. ) بين متوسطي رثب درجات الفنانات مجموعة البحث في النطبيقين القبلي، و البعدي لاختبــار التحصــيل المعرفي لصالح التطبيق البعدي.

وقد ثم حساب نسبة الكسب المعدل لبلاك لدرجات العينة مجموعــة البحــث فــي اختبــار التحصيل المعرفي، وحساب المتوسطات الحسابية لهذه النسب، وذلك باســتخدام المعادلــة

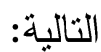

$$
\text { نسبة الكسب المعدل = د ص - س س - ص }
$$

حيث ص = مثوسط درجات الفنانات مجموعة البحث في النطبيق البعدي س = متوسط درجات الفنانات مجموعة البحث في التطبيق القبلي

د = الدرجة النهائية للمقياس

$$
\text { ويوضح الجدول( r ) نتائج ذلك: }
$$

\begin{tabular}{|c|c|c|c|}
\hline نسبة الكسب المعدل & الارجة النهائية & المتوسط & التطبيق البيانان \\
\hline \multirow{2}{*}{$1 . .9$} & \multirow{2}{*}{$r}$. & 17.49 & التطبيق القبلي \\
\hline & & r ४.०V & التطبيق البعدي \\
\hline
\end{tabular}

متوسط درجات الفناتات مجموعة البحث في التطبيقين القبلي، والبعدي لاختبار التحصيل المعرفي 
يتضح من الجدول(Y) أن نسبة الكسب المعدل لبلاك بلغت ( 9. . (1) في اختبار التحصــيل المعرفي، وهي نسبة مقبولة اظهرت تحسن في المستوى الثقافي و المعرفي للفنانــات بعـــ تطبيق البرنامج الإثرائي ، وبذلك تحقق صحة الفرض الأول .

\section{* وللتحقق من صحة الفرض الثاني :}

بنص الفرض على انه يساعد البرنامج الإثر ائي على تثمية القدر ات الإبداعية لــدى الفنانـــة التشكيلية في منطقة عسير • و على ضوء ذلك قامت الباحثة بنطبيق البرنسامج الإثرائسي للتحقق من صحة الفرض الثاني ، وبقياس ذلك من خلال : ا. قياس أعمال الفنانات التشكيلية التي تناولت الطبيعة باستخدام استمارة قيــاس الأعمــال

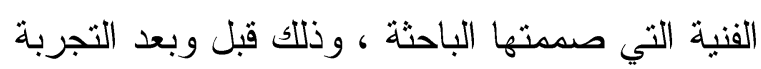

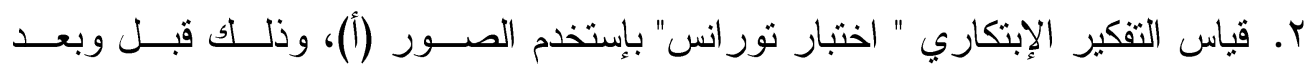
التجزبة.

تم التحقق من صحة الفرض البحثي الذي ينص علي أنه" يوجد فــرق دال إحصـــائًاً بـين منوسطي درجات الفنانات مجموعة البحث في النطبيق البعدي، و القبلي لمقيــاس الاعمــال الفنية لصالح النطبيق البعدي".

وللتحقق من صحة هذا الفرض تم استخدام اختبار (ولكوكسن) مع الأعداد الصــغيرة مــن

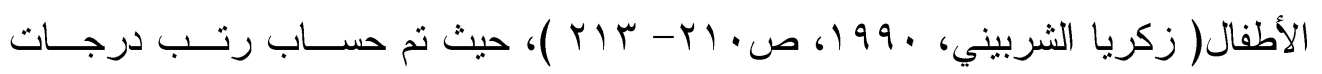

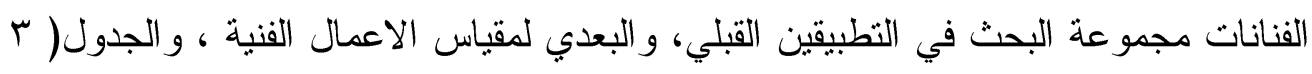
) يوضح قيمة( ) (T) )، وقيمة( Tr )، وقيمة (Z) ، ودلالتها الإحصائية للفرق بين متوسطي رثب درجات الفنانات مجموعة البحث في النطبيقين البعدي، والقبلي لمقياس الأعمال الفنية. 


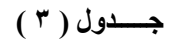

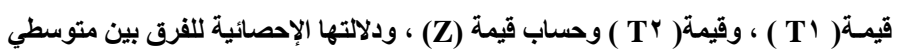

رتب درجات الفنانات مجموعة البحث في التطبيقين البعدي، والقبلي لمقياس الأعمال الفنية

\begin{tabular}{|c|c|c|c|c|c|}
\hline الإحصائية & قيمة (Z) & قيمة (Y & قيمة ('T') & العدد & \\
\hline \multirow{2}{*}{ غيتر دالة عند ه. } & \multirow[t]{2}{*}{1.79.} & \multirow[t]{2}{*}{ Y } & \multirow[t]{2}{*}{$\varepsilon$} & V & التطبيق القبلي \\
\hline & & & & v & التطبيق البعدي \\
\hline
\end{tabular}

يتضح من الجدول( r) عدم وجود فرق ذو دلالة إحصائية عنــد مسـتوى( ه. . . ) بـين متوسطي رثب درجات الفنانات مجموعة البحث في التطبيقين القبلي، و البعـدي لمقبـاس الاعمال الفنية.

وللإجابة عن السؤال البحثي: ما فاعلية برنامج مقتر ح لتتمية أداء العينة في اختبار التفكيــر الابتكاري

تم التحقق من صحة الفرض البحثي الذي ينص علي أنه" يوجد فــرق دال إحصـــائًاً بـين متوسطي درجات الطلاب مجموعة البحث في النطبيق البعدي، و القبلي لاختبـار التفكيـر الابتكاري لصالح النطبيق البعدي".

وللتحقق من صحة هذا الفرض تم استخدام اختبار (ولكوكسن) مع الأعداد الصــيرة مــن

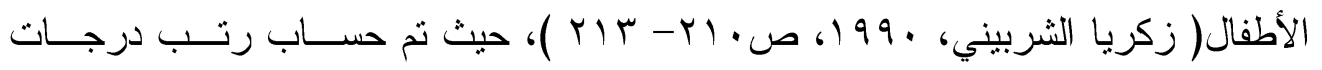

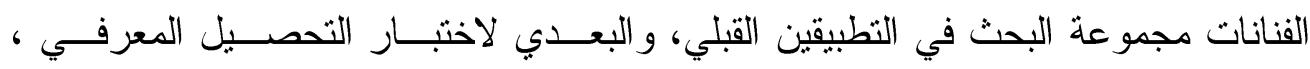

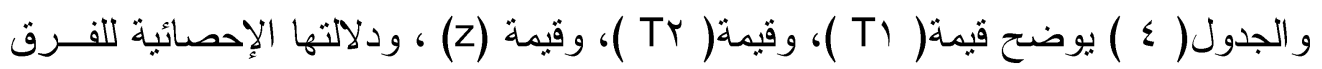
بين منوسطي رثب درجات الفنانات مجموعة البحث في التطبيقين البعدي، و القبلي لاختبـار التفكير الابتكاري. 


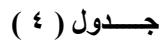

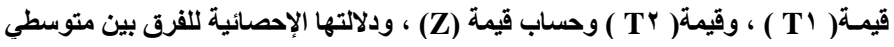

\begin{tabular}{|c|c|c|c|c|c|}
\hline الإحصائية & قيمة (Z) & قيمة (Y & قيمة (T') & العدد & \\
\hline \multirow{2}{*}{ مستوي ه د.الة عند } & \multirow[t]{2}{*}{ צ. } & \multirow[t]{2}{*}{$r \wedge$} & \multirow[t]{2}{*}{$\varepsilon$} & V & التطبيق القبلي \\
\hline & & & & $v$ & التطبيق البعدي \\
\hline
\end{tabular}

يتضح من الجدول( ؛ ) وجود فرق ذو دلالة إحصائية عند مستوى( ه... ) بين منوسطي رثب درجات الطلاب مجموعة البحث في التطبيقين القبلي، و البعـــي لاختبـار التفكيـر الابتكاري لصالح التطبيق البعدي.

وقد تم حساب نسبة الكسب المعدل لبلالك للرجات الفنانات مجموعة البحــث فــي اختبــار

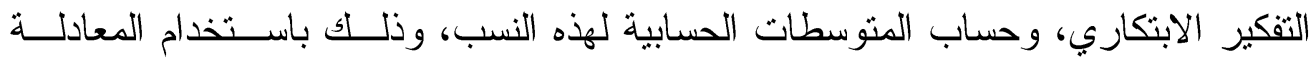

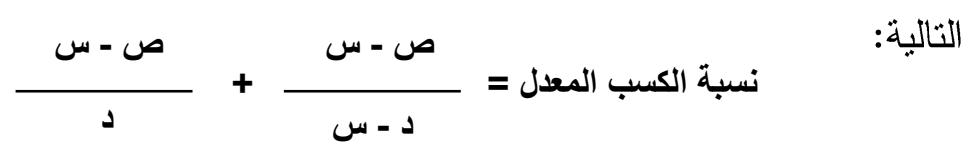

حيث ص = منوسط درجات الفنانات مجموعة البحث في النطبيق البعدي س = متوسط درجات الفنانات مجموعة البحث في النطبيق القبلي

د = الدرجة النهائية للمقياس 


$$
\text { (•) }
$$

ويوضح الجدول( 0 ) نتائج ذلك:

متوسط درجات الفنانات مجموعة البحث في التطبيقين القبلي، والبعدي لاختبار التفكير الابتكاري

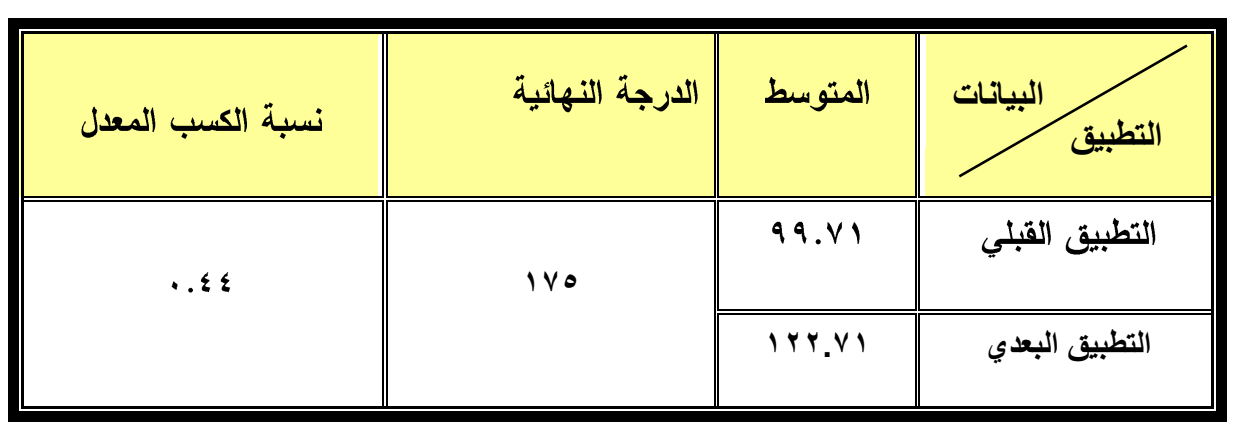

يتضح من الجدول(0) أن نسبة الكسب المعدل لبلاك بلغت ( ع ـ. •) في اختبـار التفكبـر

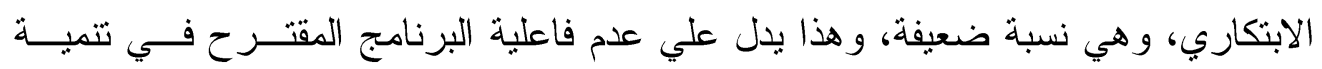
التفكير الابتكاري لدي الفنانات عينة البحث.

\section{التعقيب على التتائج :}

ا. إن در اسة بعض الاتجاهات الفنية الحديثة المبنية على نظرية الفن بوصفه مادة در اسية ساعد على إثز اء الفنانة النشكيلية ثقافيا وبصريا، الا انه يحتاج وقت زمني

$$
\text { كبيز }
$$

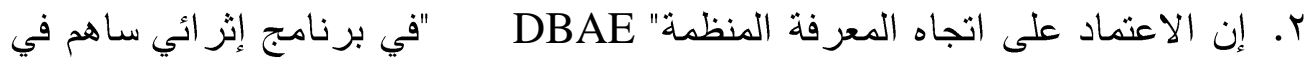
مساعدة الفنانة في فهم ومعرفه أوجه الفن التشكيلي بشكل و اضح. r. إن المستوى الثقافي و المعرفي للفنانات التشكيليات قد ارثفع بعد تطبيق البرنامج الإثز ائي.

ع. إن البناء التشكيلي و الإبداعي في إنتاج الفنانات لم يتحسن بشكل ملحوظ ، قد يكون لعدم توجيهـن مهارياً ، وكذلك رغم ضيق الوقت في إنتاج الاعمال الفنية . 
ه. عدم فاعلية البرنامج المقترح في تتمية التفكير الابتكاري لدي الفنانات عينة البحث. التوصيات :

ا. ضرورة تصميم بر امج اثز ائية في الفنون البصرية لغير المتخصصين بالفن و المناسبة

$$
\text { لقدر اتهم و استعداداتهم. }
$$

r. التزكيز على إنعاش التز اث الفني و الطبيعة بصورة معاصرة و غير تقليدية كمصدر

$$
\text { إثر ائي في بر امج الفنون البصرية. }
$$

r. عند تتظيم بر امج اثز ائية في الفنون البصرية مر اعاة أن تتضمن ورش فنية على

$$
\text { المدى الطويل لأهميتها في دعم الموهبة الفنية. }
$$

ـ. ضرورة تطبيق منل هذه البرامج في المناطق التي تفتقد وجود كلبات التربية الفنبة . ه. أهمية اعتماد نظرية المعرفة المنظمة " DBAE " في تدريس الفن من جانب الثقافة

الفنية.

\. ضرورة البحث و التأليف في طرق رعاية وتتمية الإبداع الفني بما يتتاسب مع المجتمع

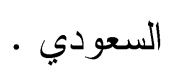

\section{قائمة المراجع والدر اسات : المات}

1- إبر اهيم ، سحر -ـ . . كم- اثز نعليم الفن على نمو الثقافة الفنبة البصرية لطــلاب كلية التزبية الفنية (رسالة ماجستير )- قسم علوم التزبية الفنية- كلية الثزبية- جامعـة حلو ان.

r- احمد، أمل-r ...rم- اثر الرؤية البصرية المباشرة للعمل الفنـي علـى مسـنتى

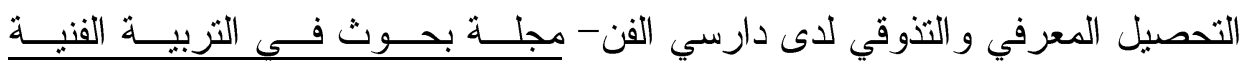

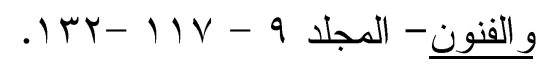

r- الحسن ،ثاج السر - 991 ام -قضايا جمالية و انسانية- بيروت - دار الجيل . ـ - الحداد، عبد الله-... . بم- سمات شخصية الطالب المبدع فــي مجــالات الفنــون

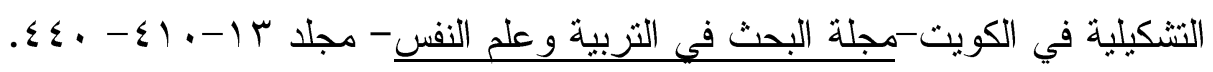


0- العمودي، يوسف-r . . بم- تطور اتجاه التربيه الفنية المبنية على الفن بوصــفه

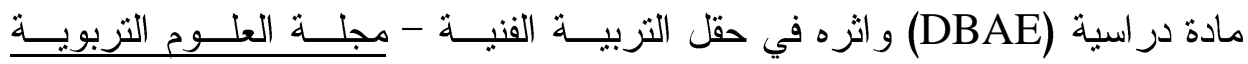

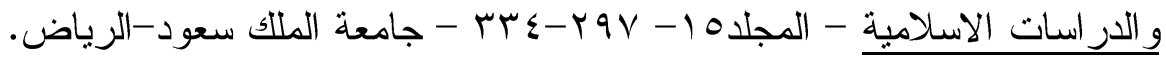
צ- حنورة ، مصري، و المشعان ،دلال-999 ام- تتمية الخيال و الإبداع من منظــور تكاملي لاى مجموعة من التلاميذ المنفقوين بدولة الكويت- المؤتمر العلمي - دمشق كلية التزبية - جامعة دمشق.

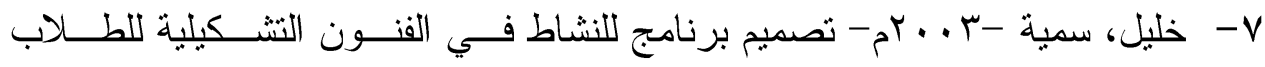
الجامعيين غير المتخصصين في الفن وفق الاتجاهات الحديثة في تعليم الفنون(رسـالة ماجستير ) - قسم علوم التزبية الفنية- كلية التزبية- جامعة حلوان - مصر . - - سرحان، منير - 199 ام- في اجتماعيات التربية -القاهرة - مكتبة الانجلو. 9- شربيني ، زكريا- ـ99 19 الإحصاء اللابار امثري في العلوم النفسية و الاجتماعيــة و التزبوية - القاهرة - مكتبة الأنجلو . لمرية • 1-صالح ، قاسم-191 ام- الإبداع في الفن - بيروت- دار الطليعة للطباعة و النشــر

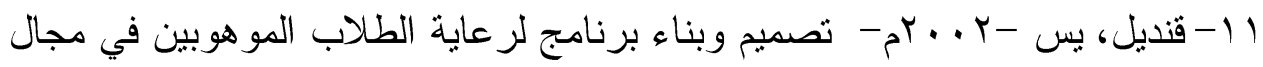
العلوم بالمملكة العربية السعودية في ضوء نموذج " عملية المنهج"- مجلة در اسات في

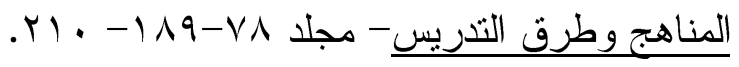
r ا - عباس، اميمة -ـ . . rم- دور الثقافة البصرية في إثراء التذوق الفني لاى فئة من الأميين(رسالة ماجستير)- قسم علوم التزبية الفنية- كلية التربية- جامعــة حلــوانمصر

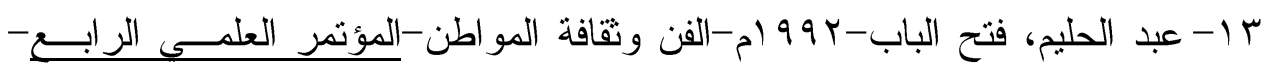




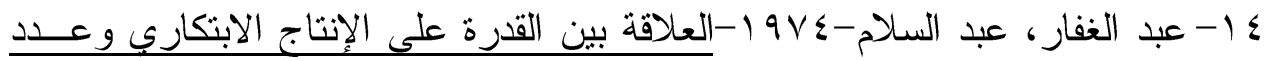
من القيم الثخصية و القيم الاجتماعية في مجال الفنون التشكيلية-القاهرة-دار النهضــة العربية.

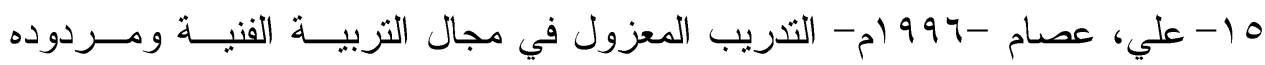

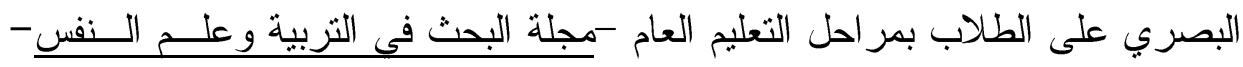

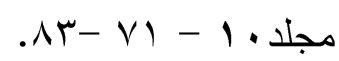

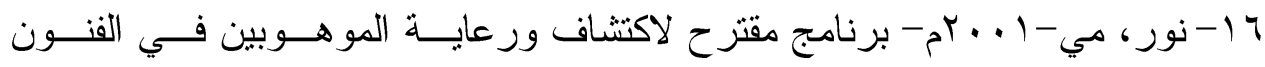

البصرية في مصر (رسالة ماجستير) -قسم علوم التزبية الفنية- كلية التزبية-جامعـة حلو ان -مصر ·

IV دار المعرفة الجامعية.

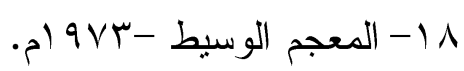

19- Kerry, Fredimin-r...r-Teaching Visual CultureCurriculum-Aesthetics and the Social Life of Art- the National Art Education Association $-\mathrm{F} \leqslant \uparrow-\lambda \mathrm{r}-\lambda\urcorner$ r.- Garber, Elizabeth-1990- Teaching Art in the Context of Culture-A Study in the Borderlands- the National Art Education Association-Frq-Y|A-rm, Y) - National Art Education Association (NAEA)-199ะThe Visual Arts Standards, Reston: National Art Education Association (NAEA). 


\section{ملخص البحث}

الفن في حد ذاته مر آة للثقافة بل احد دعاماتها، لهذا فالتقافة الفنية بمثابة الوسط الذي يعيش فيه الفنان. و البيئة تعد من العو امل التي تؤثر فيه وتحفزه للاستجابة الجمالية، ويعتبر الفن التشكيلي من أهم المجالات المعتمدة على الرؤية الفنية وخاصة البصرية. و وثقافة العين ضرورة لإدر الك العلاقات الجمالية و التي بدورها تغدي الرؤية الفنية ، ومن هذا المنطلق تترجم إلى أعمال منفذة في الفن النتكيلي. لهذا فالتقافة البصرية لدى الفنان تزيد ذخيرته من المفردات و الأشكال البصرية ، و التي تعد من المتطلبات الأساسية لتتمية المقدرة على الإبداع ، و الذي هو مطلب أساسي للفنون التشكيلية. وتزى الباحثة ضرورة رعاية المو اهب الفنية و إثر اء ثقافتها بالمدركات البصرية من خلال برنامج إثر ائي هدفه تتمية الإبداع من خلال إثر اء المدركات البصرية للفنان التشكيلي. وتتحدد مشكلة البحث في السؤال الثالي : ما اثر برنامج للثقافة البصرية على تتمية الإبداع الفني لاى بعض الفنانات التشكيليات في منطقة عسير؟ - (- من

لهذا افترضت الباحثة أن در اسة بعض الاتجاهات الفنية الحديثة المبنية على نظرية المعرفة المنظمة "DBAE" تتري الثقافة الفنية و البصرية لاى الفنانة النشكيلية في منطقة عسير. و أن هذا البرنامج الإثر ائي يساعد على تتمية القدرات الإبداعية لديهن .

اتبعت الباحثة في الدر اسة المنهج الوصفي و التجريبي، على " V " فنانات تشكيليات في منطقة عسير ، وكانت نتائج الدر اسة تشير الى إن دراسة بعض الاتجاهات الفنية الحديثة المبنية على نظرية الفن بوصفه مادة در اسية "DBAE" ساعد على إثر اء الفنانة التشكيلية ثقافيا وبصريا ،و أن تذوف أثهر الأعمال الفنية يعمل على إثز اء الثقافة البصرية، وتتمية المفاهيم الجمالية لدى الفنانة، مما يعرفها على كيفية البناء التشكيلي للعمل الفني وبالتالي تتمية التفكير الناقد و الإبداعي لديها. إن البرنامج الإثر ائي ساعد على تتمية القدر ات 
الإبداعية لدى الفنانة التشكيلية، وساهم في تحسن البناء التشكيلي، ورفع المستوى الثقافي و المعرفي لديها. ومن خلال هذه النتائج توصي الباحثة بضرورة تصميم بر امج اثر ائية في الفنون البصرية، مع ضرورة تطبيق منل هذه البرامج في المناطق التي تفتقد وجود كليات التزبية الفنية، مع أهمية اعنماد نظرية المعرفة المنظمة " DBAE " في تدريس الفن مع مر اعاة أن تتضمن ورش فنية لأهميتها و المناسبة لقدر اتهم و استعداداتهم مع ضرورة البحث و التأليف في طرق رعاية وتتمبة الإبداع الفني بما يتتاسب مع المجتمع السعودي • 


\section{Search background:}

Arts since their arise were considered a social and a beauty expression about the status of other communities in various times. They are a portrait of life, feeling, humanities Arts in itself is a mirror of a culture and one of its support and spreading means. The culture is a medium where the artist lives and the environment is considered as one of the factors that affects and stimulates him for beauty response. Eye culture is necessary to understand the aesthetic relation which would feed the artistic vision. From this notion it is translated to beautiful works in plastic arts. Thus the vision culture of the artist would increase his vocabulary with regard to words and visual shapes which are considered as a basic requirements to develop ability for innovation and excellence .which is the main requirement for plastic arts.

The researcher believed on the necessity of charring for artists skills and to enrich their culture with visual factors through programs that are targeted to develop innovation through enriching the visual concepts for the plastic artist. The research problem in limited on the following question: What is the effect of visual culture program on developing on technical innovation development for some of plastic female artist in Aseer region?

Research hypothesis is the Study of some modern t Teaching Art based on the theory of knowledge DBAE that enrich the technical and visual culture for plastic artist in Aseer region. And The enrichment program would help on developing abilities for the plastic artist.

Research methodology the research adopted the descriptive and experimental methodology for some artist in Aseer region artists. Research results is The study of some modern technical trends based on art theory with a study subject attribute DBAE" helped in enriching the plastic artist both culturally and visually. The enrichment program helped in developing the invocation abilities for plastic artist. Finally, 
Researcher Recommends The necessity of designing enrichment programs in visual arts, And the importance of organized knowledge theory adoption "DBAE" in teaching arts. and The necessity of research and writing in the methods of care and developing the technical innovation to suit the Saudi community . 